\title{
Special Issue: Transforming Early Childhood Systems for Future Generations
}

\author{
Ingrid Pramling Samuelsson ${ }^{1} \cdot$ Eunhye Park $^{2}$
}

Published online: 12 July 2017

(C) Springer Science+Business Media B.V. 2017

\section{Editorial}

At the World Conference for OMEP 2016 in Seoul, South Korea, a special issue for the journal was launched on the topic of the conference: Transforming Early Childhood Systems for Future Generations. OMEP has, for many years, worked on various topics related to sustainability and is today one of the non-government organizations (NGOs) working for UNESCO within the Global Action Program. This involves scaling-up work to involve more individuals in supporting education for sustainable development.

In this issue, we have eight articles of which two are written versions of the keynote addresses from the 2016 OMEP conference presented by Professor Sharon Lynn Kagan from the USA and Professor Arjen Wals from The Netherlands. Both of these speakers are very well known in their respective research areas; Kagan in early childhood education development and policy, and Wals on sustainability questions.

The article, Transforming Early Childhood Systems for Future Generations: Obligations and Opportunities, (Kagan and Roth) is at the center of the focus topic

Ingrid Pramling Samuelsson

ingrid.pramling@ped.gu.se

Eunhye Park

ehparkh@ewha.ac.kr

1 Department of Education, Communication and Learning, University of Gothenburg,

Läroverksgatan 15, 40530 Göteborg, Sweden

2 Department of Early Childhood Education, Ewha Womans University, 52, Ewhayeodae-gil,

Seodaemun-Gu, Seoul 120-750, Korea 
for this special IJEC issue. The authors describe a research perspective that advances thinking about how childhood systems operate, in addition to a focus on program quality. It points to the importance of a solid infrastructure to support early childhood programs. As an emerging systems perspective to early childhood education and care (ECEC), this article considers sociocultural and temporal variables that transcend traditional domains of inquiry and which could produce positive and lasting outcomes for children all over the world.

Sustainability by Default: Co-Creating Care and Relationality through Early Childhood Education (Wals) addresses the question of what it means for today's children to grow up in the Anthropocene, the current geological epoch that is shaped by Homo sapiens. Wals claims that people are aware of sustainability problems but look to their traditional ways of thinking and blame society for unsustainability. As an alternative, Wals argues for a relational approach in which people and the planet relate in other ways than how we usually talk about sustainability.

Another way to handle questions about sustainability can be found in the article, Thrown Together: Incorporating Place and Sustainability into Early Literacy Education (Schmidt). The empirical data are from Sweden and relate to questions of social inclusion for children from other cultures. By bringing place and literacy together in education the author focuses on individuals' values, beliefs, and dreams as the children learn basic literacy in Grade 1. When children compare and explore the content of texts and places within their own neighborhood, discussions can relate to their immediate communities and also the wider world on issues of sustainability.

In the article, Transforming Music Education for the Next Generation: Planting 'Four Cs' through Children's Songs (Kim), the author focuses on important skills for the twenty-first century evident in the 2014 standards for music education in the USA that include critical and creative thinking, collaboration, and communication (Four Cs). These skills can be supported by music experiences in early childhood education, including rhythm, beat, tempo, melody, and lyrics. These skills, practiced through musical activities, are viewed as transformative because they can be practiced in various curriculum areas. Music education can become more about learning domain-general skills than just music, as such.

An article from Korea (Kim and Kim) titled A Cross-National Comparison of Art Curricula for Kindergarten-Aged Children also addresses the importance of art to facilitate the holistic development of young children and their creativity. As the world increasingly converges into an integrated global community, it is important for any child to be ready to understand and respect other cultures. Authors of this article argue that since the value of art is an inseparable element of culture, it is worthwhile for any national curriculum to incorporate areas that take account of culture to broaden children's perspectives through art.

The Sustainable Development Goal 4.2 reads: “... by 2030 ensure that all girls and boys have access to quality early childhood development, care and pre-primary education so that they are ready for primary education" (United Nations 2015, p. 21). Competent early childhood teachers with skills, knowledge, dispositions, and values are of the utmost important factor for quality education. Teachers should be provided with professional opportunities for improving their competencies. Four 
articles from New Zealand, Korea, and Vietnam address teaching issues for early childhood education.

In the article, Development of Teachers' Knowledge and Skills in Implementing a Physical Education Curriculum: A New Zealand Early Childhood Intervention Study, the authors (McLachlan et al.) consider the findings from a 10-week physical activity intervention program that included teacher participation in related professional development activities to change teachers' knowledge and skills in implementing physical activities. Since obesity rates among children are increasing at an alarming rate globally, more effective teaching practices that emphasize physical activities and better nutrition are needed. This article is noteworthy in informing us that teachers need greater guidance on both physical activity and nutrition.

Pedagogical content knowledge (PCK) has been known as the one of the most important predictor for teachers to become competent in their practices. In the article, Preschool Teachers' Pedagogical Content Knowledge in Mathematics, the author (Lee) identified the construct of PCK in mathematics and measured preschool teachers' PCK. Ability to interpret and enhance children's learning is a product of teachers' knowledge of children's development, content knowledge, and teaching strategies. The author is right to argue that in order to support the development of PCK in mathematics for prospective and practicing teachers, professional development should go beyond the level of introducing mathematical content and simple or general methods of teaching mathematics. Instead, it should help teachers to identify specific mathematical situations that are evident in children's everyday activities, and the various teaching and learning strategies that 'mathematize' children's informal experience and enhance their thinking about mathematical concepts.

In the final article of the IJEC special issue, Supporting Teachers in Vietnam to Monitor Preschool Children's Well-being and Involvement in Preschool Classrooms, the authors (Lenaerts et al.) report on a professional development program involving critical reflection that was designed to better equip the teachers with pedagogical skills to enhance children's well-being and involvement and to create optimal conditions for learning in classrooms. Teachers were encouraged to change their practices to focus specifically on the learning needs of individual children in their classrooms, especially for children at risk for low engagement and involvement in learning activities.

As guest editors, with great support from the chief editor, Donna Berthelsen, to prepare this special issue on sustainability we are happy to see how sustainability is considered, on so different levels and content areas (Li et al. 2017). We see in these articles how infrastructure in ECEC can support sustainability. But also how our ways of thinking can hinder or support new ways of dealing with these issues in early childhood. By focusing on the social aspects for inclusion, multicultural questions become central (Farrell and Pramling Samuelsson 2016); but also by using what, by tradition, has been a key content in early years education, aesthetics, there are many ways to work for or with sustainability issues (Davis and Elliot 2014). 
A pathway to a more sustainable society depends on how well societies can educate the next generation. The future generation is entitled to a quality education that enables each generation to lead healthier lives and respond to local and global challenges that constitute new learning. We need systems, quality teachers, sustainable infrastructures, and curriculum to support children's learning so that children become global citizens. In this special issue of IJEC, the readers will find valuable articles that can inform these issues. Each article is worth reading to gain more information about how we could support young children to live in a sustainable world.

Eunhye Park and Ingrid Pramling Samuelsson (Editors of the Special Issue).

\section{References}

Davis, J., \& Elliot, S. (2014). Research in early childhood education for sustainability. London: Routledge.

Farrell, A., \& Pramling Samuelsson, I. (Eds.). (2016). Diversity in the early years. Intercultural learning and teaching. South Melbourne: Oxford University Press.

Li, H., Park, E., \& Chen, J. (Eds.). (2017). Early childhood education policies in the Asia Pacific: Advances in theory and practice. Singapore: Springer.

United Nations. (2015). Transforming our world: The 2030 agenda for sustainable development (A/RES/ 70/1). Retrieved from http://www.sustainabledevelopment.un.org. 